\title{
The Effect of Melting Temperature Aluminum Metal Casting Using Mixed Degasser Based Sodium Fluoride and Sodium Nitrate
}

\author{
Donanta Dhaneswara ${ }^{1}$, Jaka Fajar Fatriansyah ${ }^{1}$, Raffi Ramadhan $^{1}$, and Ahmad Ashari ${ }^{2}$ \\ ${ }^{1}$.Department of Metallurgical and Materials Engineering, Faculty of Engineering, Universitas Indonesia, \\ Kampus UI, Depok, Indonesia 16424 \\ ${ }^{2}$ Center for Materials Processing and Failure Analysis, Universitas Indonesia, Depok, Indonesia 16424
}

\begin{abstract}
The effect of $\mathrm{NaF}$ and $\mathrm{NaNO}_{3}$ based degasser on mechanical properties of $\mathrm{Al}-\mathrm{Si} 12 \%$ casting has been investigated. The quality of Al-Si casting, especially in mechanical properties, is important in some applications. However, the existence of gas porosity, which is formed due to the high solubility of $\mathrm{H}_{2}$ at melt temperature in casting process, reduces mechanical propertis of Al-Si $12 \%$ casting product. In this research, we used $\mathrm{NaF}$ and $\mathrm{NaNO}_{3}$ as degasser as an addition in casting process. The experiments were conducted at pouring temperature of $660^{\circ} \mathrm{C}, 680^{\circ} \mathrm{C}, 700^{\circ} \mathrm{C}$ and $720^{\circ} \mathrm{C}$. The mechanical properties (which are determined by tensile test, hardness test and impact test) with and without degasser were measured and compared. We found that in all pouring temperature, the addition of degasser will improve all of mecahnical properties measured. In addition we found that the increase of tensile strength was optimum at pouring temperature of $720^{\circ} \mathrm{C}$ at $25,5 \%$ of increase, hardness was optimum at pouring temperature of $720^{\circ} \mathrm{C}$ at $33,3 \%$ of increase and impact strength was optimum at pouring temperature of $720^{\circ} \mathrm{C}$ at $25 \%$ of increase. The improvement of mechanical properties is due to the role of $\mathrm{NaF}$ and $\mathrm{NaNO}_{3}$ by binding $\mathrm{H}_{2}$ gases which is formed in melting process. This $\mathrm{H}_{2}$ binding was shown in microstructure observation which shows that the porosity of casting product visually decreased.
\end{abstract}

Keywords: Al-Si12; Degasser sodium fluoride sodium nitrate, Gravity Casting

\section{Introduction}

In industries such as automotive and transportation, the use of aluminum alloys from the casting process is widely applied. However pure aluminium has relatively low mechanical properties if used for industries, so the pure aluminium has to be alloyed with other metals like silicon, copper, and magnesium to improve its mechanical properties such as hardness and strength. The use of aluminum alloys from the casting process has significant advantages, such as light weight, high castability, high specific strength, good corrosion resistance, and low shrink rate [1]-[3]. Eutectic Al-Si $12 \%$ alloys with low density, excellent castability, fit wear resistance and good hardness, are proper materials for Industries applications. The solid microstructure of Eutectic Al-Si $12 \%$ alloys be composed of $\mathrm{Si}$ phase primary, eutectic composition $(\alpha+\mathrm{Si})$ and $\alpha(\mathrm{Al})$ matrix [4]-[5].

The quality of materials from casting is determined based on temperature pouring, casting pressure, and the preheating temperature of the mold. The melting temperature is a necessary factor affecting the results of casting products. Low melting temperature causes low fluidity which can cause casting defects such as shrinkage and in the other hand, high melting temperature initiate the formation of hot cracks in the mold and forming porosity defects in the product. Moreover, high melting temperature will increase the solubility of hydrogen gas in cast products and affects the grain size of materials. Based on the effects of grain size and porosity content on the mechanical properties, the optimum melting temperature has an important role in order to decrease the grain size and porosity content from casting product [6]-[7]. Porosity is the primary defects in aluminium alloy casting and its existence is destructive for the mechanical properties of casting products [8]. Hydrogen gas is appreciably soluble in molten $\mathrm{Al}$, Thus the elimination of gas hydrogen in molten Aluminium are crucial for producing good quality castings. One of the effective way for reducing hydrogen porosity is through degassing [9]-[10]. In this paper we use mixed degasser based Sodium fluoride and Sodium nitrate, we expect that this degasser decreases porosity content by binding the $\mathrm{H}_{2}$ gas out of molten Al. 


\section{Experimental Methods}

\subsection{Making of degasser $\mathrm{NaF}$ and $\mathrm{NaNO}_{3}$}

Degasser is mainly composed by $\mathrm{NaNO}_{3}$ at concentration of $18 \mathrm{wt} \%$ in powder form and $\mathrm{NaF}$ at 40 wt $\%$. There are rest $42 \mathrm{wt} \%$ components are $\mathrm{NaCl}$, $\mathrm{NH}_{4} \mathrm{Cl}(\mathrm{KCl}), \mathrm{Na}_{2} \mathrm{SO}_{4}$, and dye. The materials were mixed with the addition of water and were put into a mixer machine with the duration of stirring is about 30 minutes. The mixed material was then processed to change the shape of the powder into a tablet degasser using printing machine. Degasser tablet then was put into the oven at temperature of $100^{\circ} \mathrm{C}$ for 1 hour for evaporating water content.

\subsection{Characterization of Al-Si 12}

The aluminium casting product were characterized by mechanical testing such as tensile test, hardness test, and impact test to find out the mechanical properties and metallography examination to obtain microstructure of aluminium casting product. The tensile testing was conducted by using GOTECH AI7000 LA 10 machine with JIS Z2241 standard. The hardness testing was conducted by using LCB3100 LECO brinell machine with $10 \mathrm{~mm}$ diameter of steel ball indentor and $500 \mathrm{kgf}$ force. To obtain the impact value, Frank impact testing machine was used with the charpy method. Preparation for metallography observation were carried out by standard metallographic procedures, started by grinding with sand paper, polishing with kovac $\left(\mathrm{TiO}_{2}\right)$ and etching with keller reagent. The composition of keller reagent is $2 \mathrm{ml} \mathrm{HF}, 5 \mathrm{ml} \mathrm{HNO}, 3 \mathrm{ml} \mathrm{HCl}$ and $190 \mathrm{ml}$ aquadest. Optical microscope was used to observed the samples. For analyze more deeply, Planimetri method was used to obtain fraction of phase porosity [11].

(a)
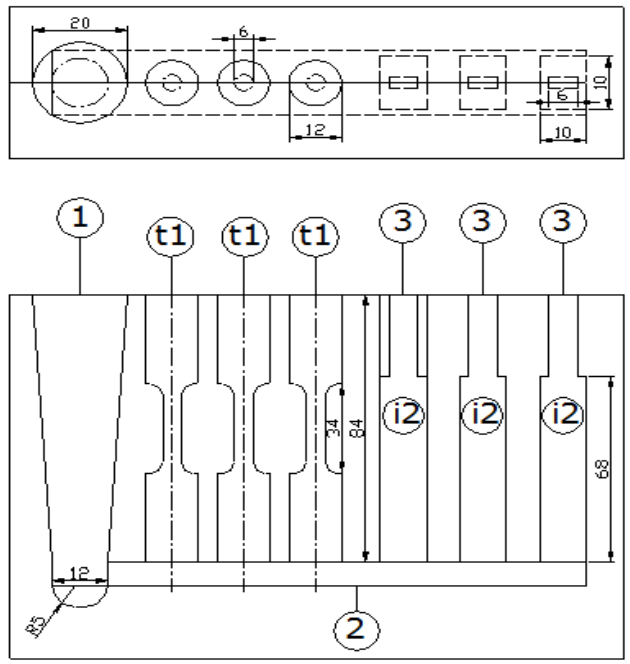

Fig. 1 Schematic of casting design. (a) Top View ; (b) Front View (1) ; Down-sprue (2); Runner (3) ; Gas Tunnel ; (t1, t2, t3) Tensile Specimen ; (i1, i2, i3) Impact Specimen.
Table 1. Chemical composition of Al-Si12 (\%)

\begin{tabular}{|c|c|c|c|c|c|c|c|}
\hline Al & $\mathbf{S i}$ & $\mathbf{F e}$ & $\mathbf{C u}$ & Mn & Mg & $\mathbf{Z n}$ & $\mathrm{Cr}$ \\
\hline 87. & 12. & 0.09 & 0.00 & 0.00 & 0.00 & 0.002 & 0.00 \\
\hline 3 & 4 & 38 & 15 & 45 & 03 & 40 & 48 \\
\hline
\end{tabular}

Fig. 1 shows the schematic design of metal mold. The specimen of this experiment was determined on a design used metal mold casting. The experiment was conducted in foundry laboratory metallurgical and material engineering departments. Casting products was obtained from metal mold are shown in $\mathrm{t} 1, \mathrm{t} 2, \mathrm{t} 3$ and i1, i2, i3 which will serve as sample specimen in testing the mechanical properties cast products. Down sprue which shown at number 1 was located in the left side of casting with a diameter $20 \mathrm{~mm}$. down sprue is a place of pouring molten metal into a metal mold. Runner which shown at number 2, as where the molten metal flows fills the sample's tensile and impact casting. Gas tunnel which shown at number 3 was located in the right side of casting, as a place for removing gas from within the metal mold. After casting was finished, the sample of the specimen was observed to probe the 1 properties of the casting material.

\section{Results and Discussion}

\subsection{Mechanical properties of casting Al-Si 12 with degasser}

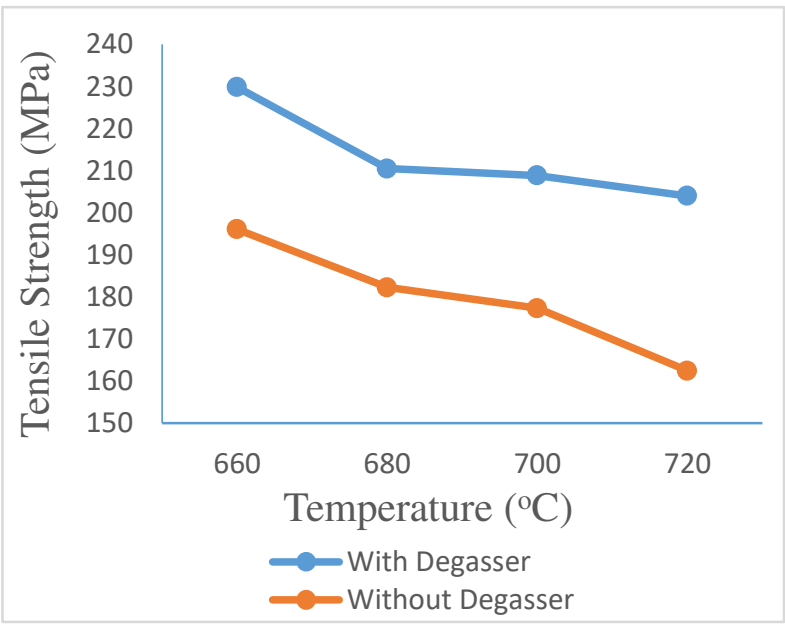

Fig. 2 Effect of degasser $\mathrm{NaF}$ and $\mathrm{NaNO}_{3}$ addition on tensile strength of Al-Si $12 \%$ 


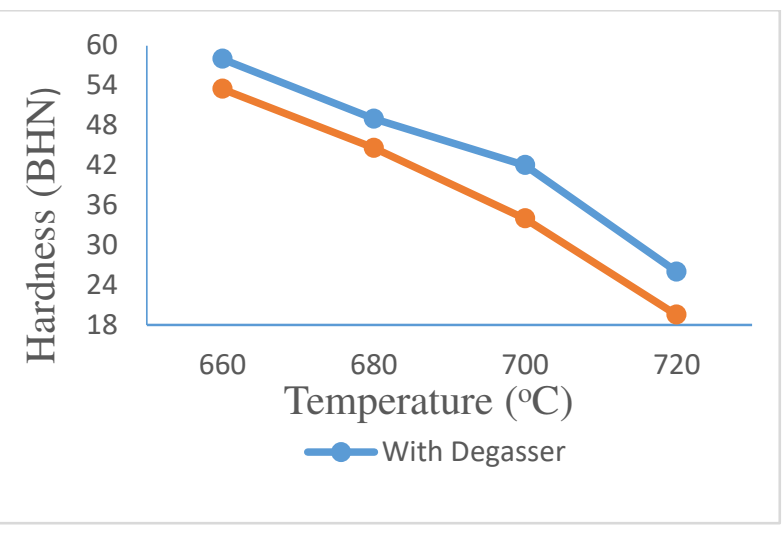

Fig. 3 Effect of degasser $\mathrm{NaF}$ and $\mathrm{NaNO}_{3}$ addition on hardness of Al-Si $12 \%$

The results of tensile tests are shown in Fig. 2. From the figure shows that effect of degasser $\mathrm{NaF}$ and $\mathrm{NaNO}_{3}$ addition has important effects for tensile properties. Porosity in castings represent a significant role in increasing the mechanical properties [12]-[13]. The existence of hydrogen gas in casting product decreases the mechanical properties like tensile strength of the materials [14]. From figure 1, it was shown that the degasser addition yields higher tensile strength. The tensile strength increased $17,2 \%, 15,5 \%$, $17,7 \%, 25,5 \%$ at temperatures of $660^{\circ} \mathrm{C}, 680^{\circ} \mathrm{C}, 700^{\circ} \mathrm{C}$ and $720^{\circ} \mathrm{C}$ respectively. The effect of degasser, in this case was found to be effective at pouring temperature of $720^{\circ} \mathrm{C} . \mathrm{NaF}$ and $\mathrm{NaNO}_{3}$ in degasser binds $\mathrm{H}_{2}$ gas from the molten metal forming other compounds so the porosity is reduced and the tensile strength increases.

Fig. 3 shows the results of hardness tests. The results show with the addition of degasser it will increses the hardness of the aluminium alloy casting product. The most major factor that affect the hardness is porosity, as the porosity amount increase it would decrease the hardness of casting product. [15]-[17]. The hardness increased $8,4 \%, 9,8 \%, 23,5 \%, 33,3 \%$ at temperatures of $660^{\circ} \mathrm{C}, 680^{\circ} \mathrm{C}, 700^{\circ} \mathrm{C}$ and $720^{\circ} \mathrm{C}$ respectively. The effect of degasser, in this case was found to be effective at pouring temperature of $720^{\circ} \mathrm{C}$. Effect addition of degasser is reduced porosity and make the SDAS (secondary dendritic arm spacing) become smaller and it is increasing the hardness [18].

Fig.4 shows the impact strength values for both alloys with degasser and without addition of degasser. The impact strength plays a significant role in particular applications. It can estimate the ductility of an aluminium alloy casting product under the conditions of rapid loading [19]. One of the advantages that was obtained from modification alloy is improved ductility [20]. The addition of degasser increases strength and may improve ductilty. The impact strength increased $20,5 \%, 11,1 \%, 15,4 \%, 25 \%$ at temperatures of $660^{\circ} \mathrm{C}, 680^{\circ} \mathrm{C}, 700^{\circ} \mathrm{C}$ and $720^{\circ} \mathrm{C}$ respectively. The effect of degasser, in this case was found to be effective at pouring temperature of $720^{\circ} \mathrm{C}$.

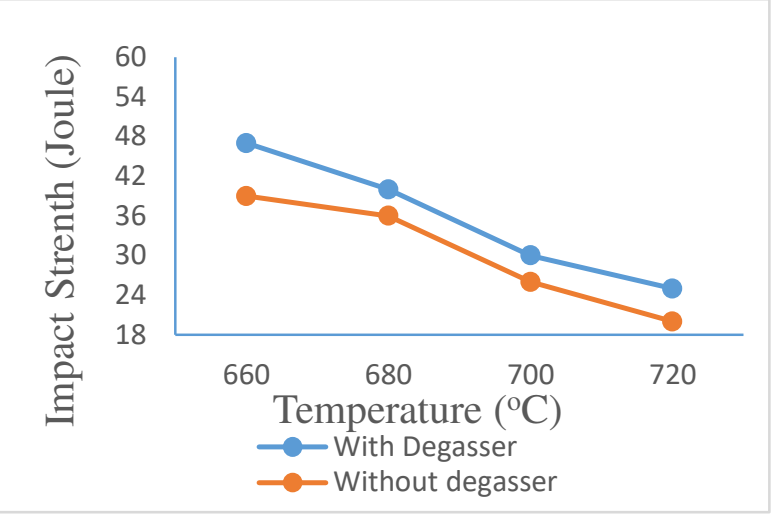

Fig. 4 Effect of Degasser $\mathrm{NaF}$ and $\mathrm{NaNO}_{3}$ addition on Impact strength of Al-Si $12 \%$

\subsection{Microsctructural observation and phase identification of Al-Si12}

Fig. 5 shows the porosity level structure of Al-Si $12 \%$ eutectic alloy at its various melting temperature. Aluminum molten metal was poured into the cup then was put on the porosity meter. The pressure was lowered for 315 seconds in accordance with the standard. The vacuum was applied for 5 minutes and 15 seconds is needed to reach the applied pressure. The pressure of the porosity meter is $-100 \mathrm{mmHg}$, which is an optimum vacuum pressure for measurements. From the visual observation based on figure 5 , it can be easily observed that the addition of degasser reduces the pores.

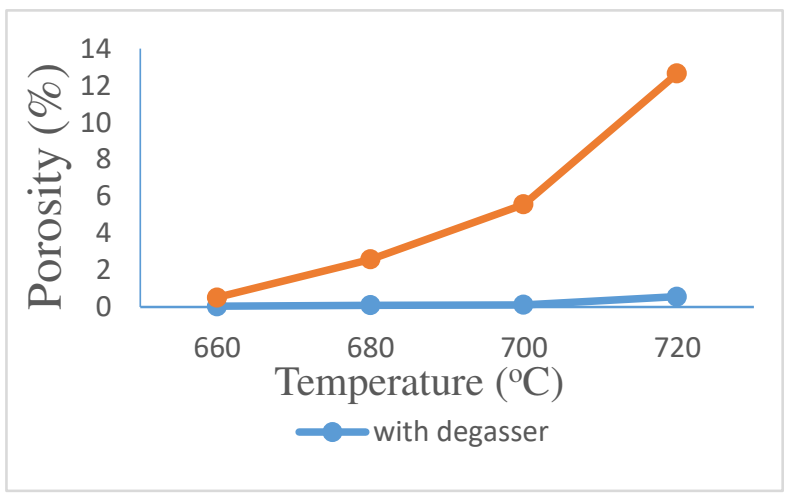

Fig 7. Fraction of phase porosity Al-Si12 with degasser and non degasser at variation temperature

The microstructure of $\mathrm{Al}-\mathrm{Si} 12 \%$ eutectic alloy at temperatures $660{ }^{\circ} \mathrm{C}$ was shown in Fig.6. The small amount of the elongated primary $\mathrm{Si}$ and large number of dendritic $\alpha-\mathrm{Al}$ phase in aluminium alloys was found in Fig.6. [20]. On the microstructure of Al-Si $12 \%$ eutectic alloy with the addition of degasser $\mathrm{NaF}$ and $\mathrm{NaNO}_{3}$, at modified temperature $660^{\circ} \mathrm{C}$ The fraction zone of primary $\mathrm{Si}$ and $\alpha-\mathrm{Al}$ reached the maximum, and the content porosity that occurs is very low or almost nonexistent due to the hydrogen gas in the melting aluminum binding with the compounds present in the degasser. Fig. 7 shows the fraction of phase 
porosity of $\mathrm{Al}-\mathrm{Si} 12 \%$ eutectic alloy. Calculation fraction of phase porosity using planimetry method. Al-Si $12 \%$ with the addition of degasser $\mathrm{NaF}$ and $\mathrm{NaNO}_{3}$, fraction of phase porosity is very low from the whole phase. Low porosity at Al-Si12\% eutectic alloy cause the effect of addition degasser $\mathrm{NaF}$ and $\mathrm{NaNO}_{3}$. With the addition of degasser, hydrogen gas in the
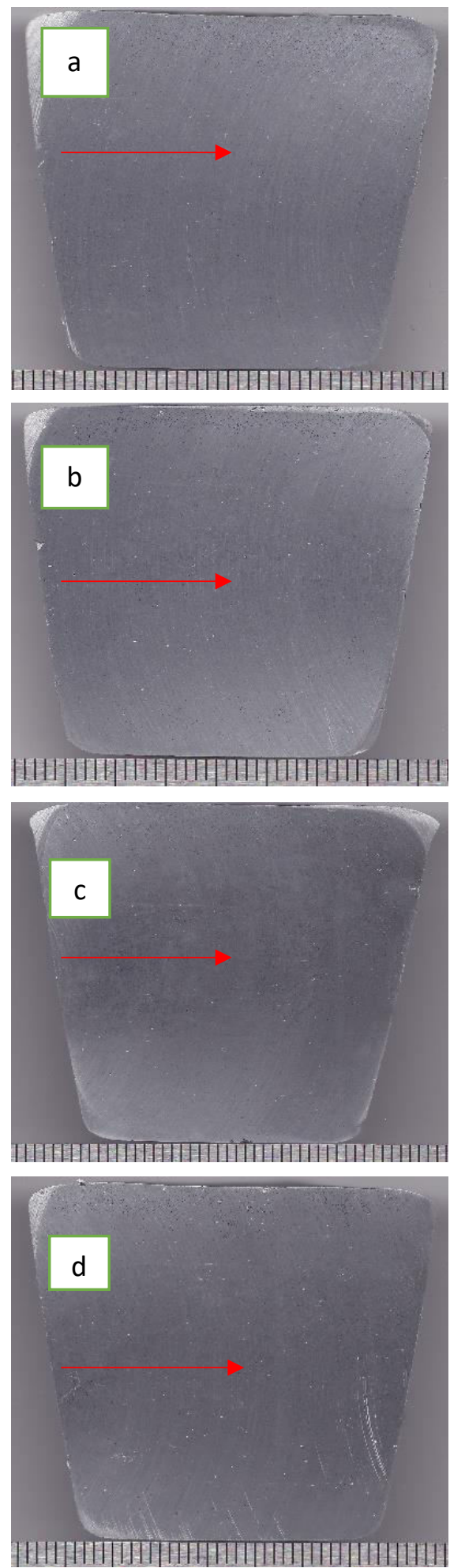

molten metal decrease cause compound degasser bind the $\mathrm{H}_{2}$ gas. Al-Si12\% without the addition of degasser, fraction of phase porosity is high than with the addition of degasser from the whole phase. This is due to the solubility of $\mathrm{H}_{2}$ gas in molten aluminum is still high so susceptible to porosity.
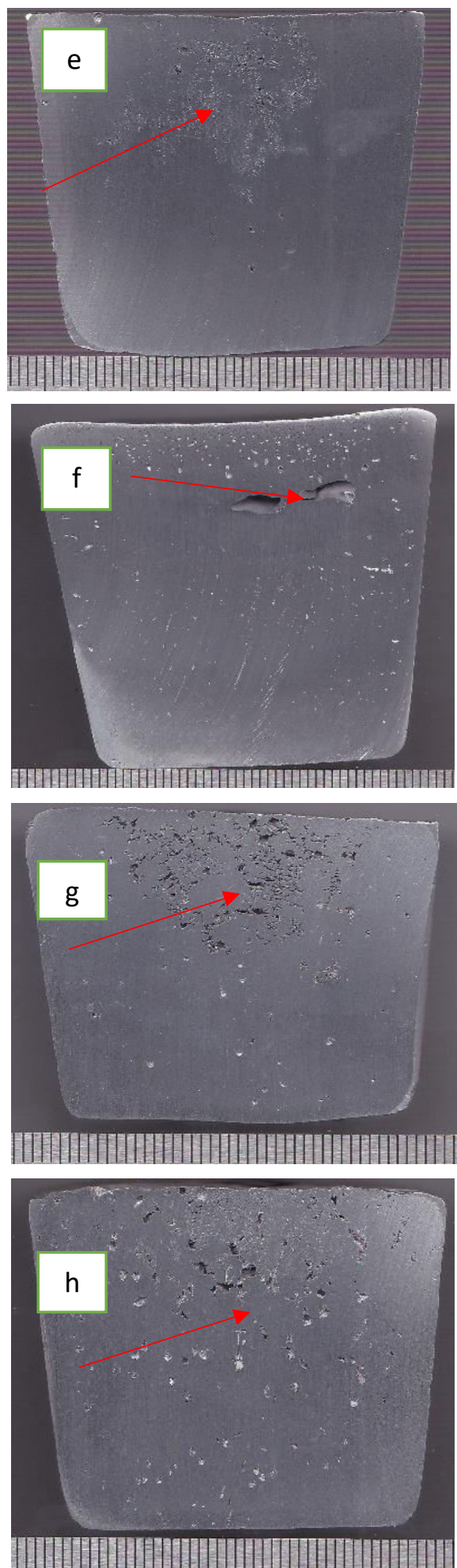

Fig 5. Macrostructur of porosity level of casting Al-Si12 with degasser at variation temperature: (a) $660^{\circ} \mathrm{C}$; (b) $680^{\circ} \mathrm{C}$; (c) $700^{\circ} \mathrm{C}$; (d) $720^{\circ} \mathrm{C}$ and non degasser at variation temperature: (e) $660^{\circ} \mathrm{C}$; (f) $680^{\circ} \mathrm{C}$; (g) $700^{\circ} \mathrm{C}$; (h) $720^{\circ} \mathrm{C}$ 

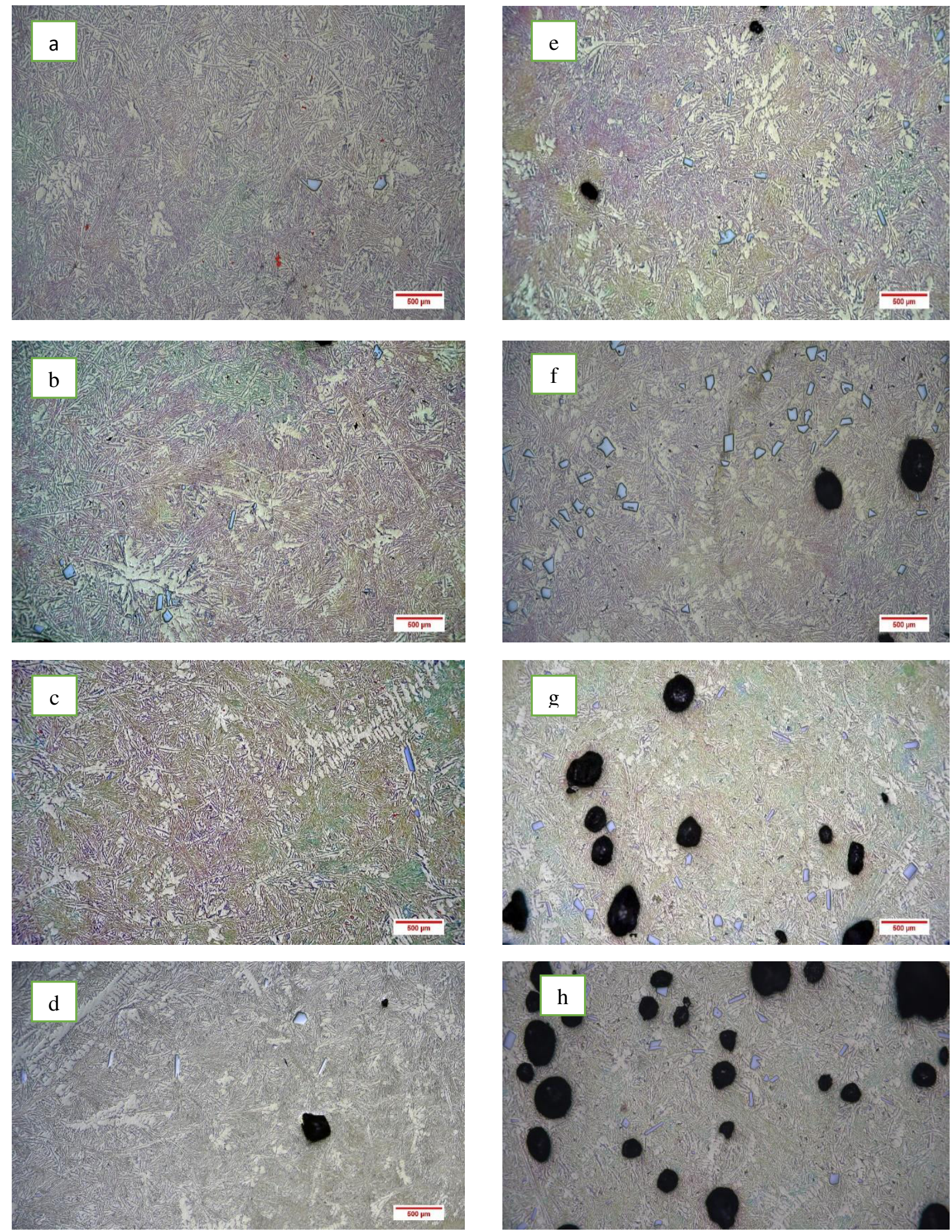

Fig 6. Microstructure of casting Al-Si12 with degasser at variation temperature: (a) $660^{\circ} \mathrm{C}$; (b) $680^{\circ} \mathrm{C}$; (c) $700^{\circ} \mathrm{C}$; (d) $720^{\circ} \mathrm{C}$ and non degasser at variation temperature: (e) $660^{\circ} \mathrm{C}$; (f) $680^{\circ} \mathrm{C}$; (g) $700^{\circ} \mathrm{C}$; (h) $720^{\circ} \mathrm{C}$. 


\subsection{Effect of Sodium fluoride and Sodium nitrate} addition

$$
\begin{aligned}
& 2 \mathrm{NaF}+\mathrm{H}_{2} \Rightarrow 2 \mathrm{Na}+2 \mathrm{HF} \\
& 2 \mathrm{NaNO}_{3}+\mathrm{H}_{2} \Rightarrow 2 \mathrm{Na}+2 \mathrm{HNO}_{3}
\end{aligned}
$$

The effect of addition degasser $\mathrm{NaF}$ and $\mathrm{NaNO}_{3}$ can be inferred from chemical reactions in equation (1) and (2). The function of the compound contained in the degasser is to produce nitrogen gas when immersed into an molten aluminum. The presence of $\mathrm{N}_{2}$ gas and bubbles formed will bind $\mathrm{H}_{2}$ gas by diffusing $\mathrm{H}_{2}$ gas into the bubbles and carrying $\mathrm{H}_{2}$ gas to the molten aluminum surface. From the equation (1) and (2) we can conclude that the compound on the degasser can also bind impurities in the molten aluminum to oxide which will rise to the molten aluminum surface and disposed as a dross. The content porosity in metal is decreased and the mechanical properties of aluminum casting metal aluminum surface. From the equation (1) and (2) we can conclude that the compound on the degasser can also bind impurities in the molten aluminum to oxide which will rise to the molten aluminum surface and disposed as a dross. The content porosity in metal is decreased and the mechanical properties of aluminum casting metal product increased with the addition of degasser sodium fluoride and sodium nitrate.

\section{Conclusion}

Addition of degasser $\mathrm{NaF}$ and $\mathrm{NaNO}_{3}$ improves mechanical properties of $\mathrm{Al}-\mathrm{Si} 12 \%$ eutectic alloy such as tensile strength, impact strength, and hardness. This is due to the role of degasser in reduce gas porosity based on microstructure observation. The mechanism reducing of gas porosity, is that these degasser compounds bind $\mathrm{H}_{2}$ gas from molten aluminum as shown in equation (1) and (2).

The authors gratefully acknowledge financial support provided by Hibah PITTA with contract 2421/UN2.R3.1/HKP.05.00/2018.

\section{Reference}

1. Cao, H., Hao, M., Shen, C., \& Liang, P. The influence of different vacuum degree on the porosity and mechanical properties of aluminum die casting. Vacuum, 146, 278-281 (2017)

2. Fan, K. L., He, G. Q., Liu, X. S., Liu, B., She, M., Yuan, Y. L., ... Lu, Q. Tensile and fatigue properties of gravity casting aluminum alloys for engine cylinder heads. Materials Science and Engineering A, 586, 78-85 (2013)

3. Santosh, M. V., Suresh, K. R., \& Kiran Aithal, S. Mechanical Characterization and Microstructure analysis of Al C355.0 by Sand Casting, Die Casting and Centrifugal Casting Techniques. Materials Today: Proceedings, 4(10), 10987-10993 (2017)

4. Li, R., Liu, L., Zhang, L., Sun, J., Shi, Y., \& Yu, B. Effect of Squeeze Casting on Microstructure and Mechanical Properties of Hypereutectic Al-xSi Alloys. Journal of Materials Science and Technology, 33(4), 404-410 (2017)

5. Qi, M., Kang, Y., Qiu, Q., Tang, W., Li, J., \& Li, B. Microstructures, mechanical properties, and corrosion behavior of novel high-thermal-conductivity hypoeutectic Al-Si alloys prepared by rheological high pressure die-casting and high pressure diecasting. Journal of Alloys and Compounds, 749, 487502 (2018)

6. Jahangiri, A., Marashi, S. P. H., Mohammadaliha, M., \& Ashofte, V. The effect of pressure and pouring temperature on the porosity, microstructure, hardness and yield stress of AA2024 aluminum alloy during the squeeze casting process. Journal of Materials Processing Technology, 245, 1-6 (2017)

7. Yu, W., Zhao, H., Wang, L., Guo, Z., \& Xiong, S. The influence of T6 treatment on fracture behavior of hypereutectic Al-Si HPDC casting alloy. Journal of Alloys and Compounds, 731, 444-451 (2018)

8. Zhao, L., Pan, Y., Liao, H., \& Wang, Q. Degassing of aluminum alloys during re-melting. Materials Letters, 66(1), 328-331 (2012)

9. Haghayeghi, R., Bahai, H., \& Kapranos, P. Effect of ultrasonic argon degassing on dissolved hydrogen in aluminium alloy. Materials Letters, 82, 230-232 (2012)

10. Ren, Y., Ma, W., Wei, K., Yu, W., Dai, Y., \& Morita, K. Degassing of aluminum alloys via the electromagnetic directional solidification. Vacuum, 109, 82-85 (2014)

11. Dhaneswara, D., Syahrial, A, Z., Ayman, M, T. Mechanical Properties of Nano SiC-Reinforced Aluminum A336 with Sr Modifier Fabricated by Stir Casting Method. Procedia Engineering, 216, 43-50 (2017)

12. Tzeng, Y.-C., \& Jian, S.-Y. Effects of the addition of trace amounts of $\mathrm{Sc}$ on the microstructure and mechanical properties of Al-11.6Si alloys. Materials Science and Engineering: A, 723, 22-28 (2018).

13. Jung, J. G., Lee, S. H., Cho, Y. H., Yoon, W. H., Ahn, T. Y., Ahn, Y. S., \& Lee, J. M. Effect of transition elements on the microstructure and tensile properties of Al-12Si alloy cast under ultrasonic melt treatment. Journal of Alloys and Compounds, 712, 277-287 (2017)

14. Puga, H., Barbosa, J., Tuan, N. Q., \& Silva, F. Effect of ultrasonic degassing on performance of Al-based components. Transactions of Nonferrous Metals Society of China (English Edition), 24(11), 34593464 (2014) 
15. Lin, Y. C., Luo, S. C., Huang, J., Yin, L. X., \& Jiang, $X$. Y. Effects of solution treatment on microstructures and micro-hardness of a Sr-modified Al-Si-Mg alloy. Materials Science and Engineering A, 725, 530-540 (2018)

16. Costa, T. A., Dias, M., Gomes, L. G., Rocha, O. L., \& Garcia, A. Effect of solution time in T6 heat treatment on microstructure and hardness of a directionally solidified $\mathrm{Al}-\mathrm{Si}-\mathrm{Cu}$ alloy. Journal of Alloys and Compounds, 683, 485-494 (2016)

17. Rejaeian, M., Karamouz, M., Emamy, M., \& Hajizamani, M. Effects of Be additions on microstructure, hardness and tensile properties of A380 aluminum alloy. Transactions of Nonferrous Metals Society of China (English Edition), 25(11), 3539-3545 (2015)

18. Ceschini, L., Morri, A., Toschi, S., Johansson, S., \& Seifeddine, S. Microstructural and mechanical properties characterization of heat treated and overaged cast A354 alloy with various SDAS at room and elevated temperature. Materials Science and Engineering A, 648, 340-349 (2015)

19. Abuhasel, K. H. A., Ibrahim, M. F., Elgallad, E. M., \& Samuel, F. H. On the impact toughness of Al-Si cast alloys. Materials and Design, 91, 388-397 (2016).

20. Samuel, E., Golbahar, B., Samuel, A. M., Doty, H. W., Valtierra, S., \& Samuel, F. H. Effect of grain refiner on the tensile and impact properties of Al-SiMg cast alloys. Materials and Design, 56, 468-479 (2014).

21. Samuel, E., Golbahar, B., Samuel, A. M., Doty, H. W., Valtierra, S., \& Samuel, F. H. Effect of grain refiner on the tensile and impact properties of $\mathrm{Al}-\mathrm{Si}$ Mg cast alloys. Materials and Design, 56, 468-479 (2014). 